\title{
Interaction and Lipid-Induced Conformation of Two Cecropin-Melittin Hybrid Peptides Depend on Peptide and Membrane Composition
}

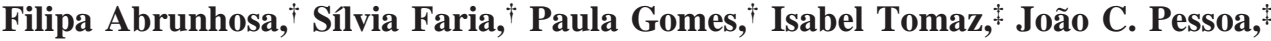 \\ David Andreu, ${ }^{\S}$ and Margarida Bastos ${ }^{*}, \uparrow$ \\ CIQ (U.P.) Department of Chemistry, Faculty of Sciences, University of Porto, P-4169-007 Porto, Portugal, \\ Centro de Química Estrutural / Instituto Superior Técnico, UTL, P-1049-001 Lisboa, Portugal, and Department \\ of Experimental and Health Sciences, Universitat Pompeu Fabra, E-08003 Barcelona, Spain
}

Received: March 28, 2005; In Final Form: June 3, 2005

\begin{abstract}
The interaction of two hybrid peptides of cecropin A and melittin $[\mathrm{CA}(1-8) \mathrm{M}(1-18)$ and $\mathrm{CA}(1-7) \mathrm{M}(2-$ 9)] with liposomes was studied by differential scanning calorimetry (DSC), circular dichroism (CD), and quasi-elastic light scattering (QELS). The study was carried out with large unilamellar vesicles (LUVs) of three different lipid compositions: 1,2-dimyristoil-sn-glycero-3-phosphocholine (DMPC), 1,2-dimyristoylsn-glycero-3-phospho-rac-(1-glycerol) (DMPG) and a binary mixture of DMPC/DMPG, in a wide range of peptide-to-lipid (P:L) molar ratios (0 to 1:7). DSC results indicate that, for both peptides, the interaction depends on membrane composition, with very different behavior for zwitterionic and anionic membranes. CD data show that, although the two peptides have different secondary structures in buffer (random coil for $\mathrm{CA}(1-7) \mathrm{M}(2-9)$ and predominantly $\beta$-sheet for $\mathrm{CA}(1-8) \mathrm{M}(1-18))$, they both adopt an $\alpha$-helical structure in the presence of the membranes. Overall, results are compatible with a model involving a strong electrostatic surface interaction between the peptides and the negatively charged liposomes, which gives place to aggregation in the gel phase and precipitation after a threshold peptide concentration. In the case of zwitterionic membranes, a progressive surface coverage with peptide molecules destabilizes the membrane, eventually leading to membrane disruption. Moreover, delicate modulations in behavior were observed depending on the peptide.
\end{abstract}

\section{Introduction}

Eukaryotic antibiotic peptides (EAPs) are important components of the nonadaptative immune system. These antimicrobial peptides have been widely studied for the past years, ${ }^{1-4}$ as they may become an alternative to conventional antibiotic therapy, in view of the growing emergence of multiresistant microbial strains. Substantial efforts have been directed to increase the potency and specificity of these peptides against pathogenic bacteria, while minimizing their cytotoxic effect toward eukaryotic cells.

One particularly successful approach is based on hybrid sequences derived from naturally occurring $\alpha$-helical EAPs. ${ }^{5}$ Cecropin A (CA) and melittin (M) provided the first examples of EAP sequence hybridization. ${ }^{6-8} \mathrm{CA}(1-8) \mathrm{M}(1-18)$, one of the most successful examples of the hybridization concept, showed improved antimicrobial activity relative to parent cecropin A and greatly reduced the hemolytic properties of melittin. Taking $\mathrm{CA}(1-8) \mathrm{M}(1-18)$ as lead, a subsequent approach was to further reduce the size of the hybrid $\mathrm{CA}-\mathrm{M}$ peptides while retaining antimicrobial activity. This led to CA$(1-7) \mathrm{M}(2-9),{ }^{9}$ a pentadecapeptide that preserves most of the activity of $\mathrm{CA}(1-8) \mathrm{M}(1-18)$.

Both $\mathrm{CA}(1-8) \mathrm{M}(1-18)$ and $\mathrm{CA}(1-7) \mathrm{M}(2-9)$ have been extensively studied in terms of antimicrobial activity. ${ }^{10-14}$ Their amino acid sequences, along with those of the parent peptides

* To whom correspondence should be addressed: Fax: +351-226082959; E-mail: mbastos@fc.up.pt.

University of Porto.

$\doteqdot$ Centro de Química Estrutural/Instituto Superior Técnico.

$\S$ Universitat Pompeu Fabra. cecropin A and melittin, are shown in Table 1, and their helical wheel and $\beta$-sheet projections are displayed in Figure 1. Both hybrids share the cationic N-terminus of cecropin A followed by the hydrophobic N-terminus of melittin, but $\mathrm{CA}(1-8) \mathrm{M}$ $(1-18)$ has a larger hydrophobic domain than CA $(1-7) \mathrm{M}(2-$ 9). The permeabilization of artificial membranes by $\mathrm{CA}(1-$ 8)M(1-18) has been studied by Mancheño et al. ${ }^{15}$ The characteristics of the peptide-membrane interaction process are dependent on the charge properties of the membrane and can be used to interpret the specificity of peptide activity against bacteria, which possess negatively charged membranes. ${ }^{16}$ Other investigations on microorganisms confirmed that, generally, antimicrobial peptides exert their activity by permeabilizing the plasma membrane..$^{3,11,17,18}$ Alternative mechanisms of action have been proposed for some antimicrobial peptides, ${ }^{4,19-28}$ and the requirements for peptide antimicrobial activity have also been extensively discussed. . $^{3,29-33}$

Differential scanning calorimetry (DSC) has emerged as a most valuable tool to study peptide-membrane interactions. ${ }^{28,30,34-39}$ DSC analysis provides a thermodynamic characterization of the changes induced by peptides on liposome phase transitions. The size and charge of the lipid vesicles can also be affected by the presence of membrane-active peptides, which can be monitored by physical techniques such as quasielastic light scattering (QELS). On the other hand, membrane interfaces have the ability to induce secondary structure in a wide range of antimicrobial peptides, ${ }^{19,31,32,40}$ and this can be evaluated by circular dichroism (CD) spectroscopy. Although CD spectra recorded in the presence of lipid systems only provide a weighed average of the membrane-bound and free peptide conformations, both conventional $\mathrm{CD}$ and oriented 


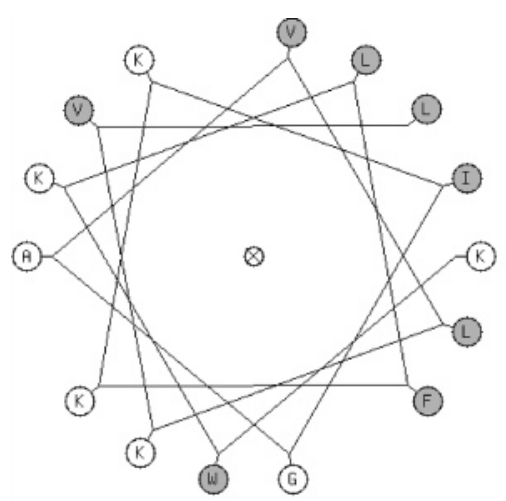

$\mathrm{CA}(1-7) \mathrm{M}(2-9)$

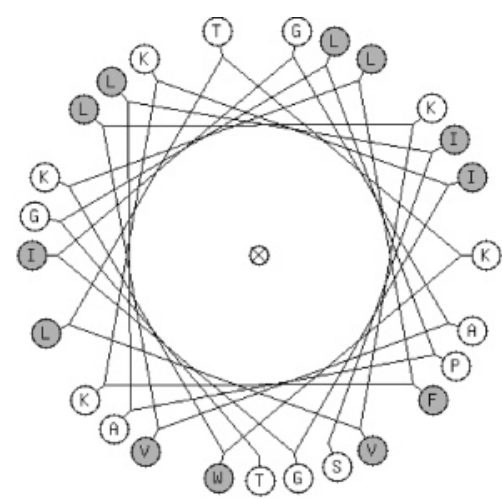

$\mathrm{CA}(1-8) \mathrm{M}(1-18)$

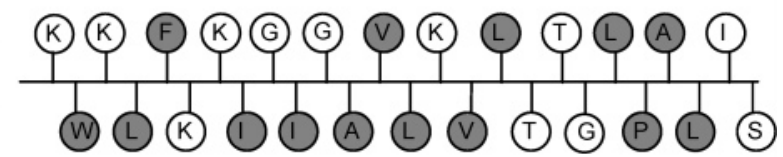

Figure 1. Helical wheel and $\beta$-strand diagrams showing the distribution of amino acid side chains: gray, hydrophobic residues; white, hydrophilic residues.

TABLE 1: Sequences of Cecropin A, Melittin, and the Hybrid Peptides CA(1-8)M(1-18) and CA(1-7)M(2-9)

\begin{tabular}{|c|c|}
\hline peptide & sequence \\
\hline $\begin{array}{l}\text { cecropin A } \\
\text { melittin } \\
\text { CA }(1-7) \mathrm{M}(2-9) \\
\mathrm{CA}(1-8) \mathrm{M}(1-18)\end{array}$ & 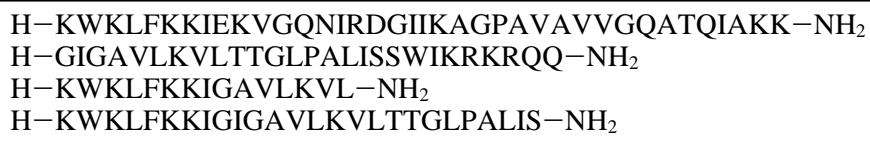 \\
\hline
\end{tabular}

circular dichroism (OCD) have been proven useful for the analysis of peptide conformational changes upon interaction with model membranes. ${ }^{27,31,32,41,42}$

We herein report the study of the interactions between the antimicrobial peptides $\mathrm{CA}(1-8) \mathrm{M}(1-18)$ and $\mathrm{CA}(1-7) \mathrm{M}(2-$ 9) and large unilamellar vesicles (LUVs) of three different lipid bilayer systems: zwitterionic DMPC, anionic DMPG, and a DMPC/DMPG 3:1 mixture. The study was carried out by DSC, QELS, and CD, so that the effect of the peptides on vesicle thermotropic phase behavior (DSC), charge, and size (QELS) could be related to membrane-induced changes in peptide structure (CD). The establishment of such relations, and of the importance of peptide and membrane composition in the interaction processes, is a valuable contribution to the understanding of the mechanisms of antimicrobial action of $\mathrm{CA}-\mathrm{M}$ hybrids and to the future design of novel antimicrobial peptides based in the hybridization concept.

\section{Experimental Methods}

Materials. DMPC (1,2-dimyristoyl-sn-glicero-3-phosphocholine) and DMPG (1,2-dimyristoyl-sn-glycero-3-[phosphorac-(1-glycerol)]) were obtained from Avanti Polar Lipids (Alabaster, AL) and used without further purification. Fmocprotected amino acids, coupling reagents, and resins for solidphase peptide synthesis were purchased from Nova Biochem (Switzerland). All other reagents were from Sigma Chemical Co. (St. Louis, MO).

Peptide solutions and liposome suspensions were prepared in HEPES buffer ( $N$-(2-hydroxyethyl) piperazine- $N$-ethanesulfonic acid). Ultrapure water (Milli Q Gradient, Millipore, Billerica, MA) was used in the preparation of all samples.

Preparation of Liposomes. Appropriate amounts of phospholipids (DMPC, DMPG, and DMPC/DMPG (3:1)) were dissolved in chloroform (DMPC) or cloroform/methanol (3:1 v/v) (DMPG and DMPC/DMPG (3:1)). The samples were then dried under a nitrogen stream, and the film was kept under vacuum for $3 \mathrm{~h}$ to remove all traces of organic solvents. The resulting lipid film was warmed together with HEPES buffer in a thermostated water bath at ca. $10{ }^{\circ} \mathrm{C}$ above the temperature of the gel-to-liquid crystalline phase transition $\left(T_{\mathrm{m}}\right)$ and then hydrated at the same temperature. The multilamellar vesicles (MLVs) thus obtained were frozen in liquid nitrogen and thawed in a water bath at ca. $10{ }^{\circ} \mathrm{C}$ above $T_{\mathrm{m}}$, and this process was repeated five times.

Large unilamellar vesicles (LUVs) were obtained from the MLVs by extrusion in a $10 \mathrm{~mL}$ stainless steel extruder (Lipex Biomembranes, Vancouver, BC, Canada), inserted in a thermostated cell with a recirculating water bath, at ca. $10{ }^{\circ} \mathrm{C}$ above $T_{\mathrm{m}}$. The samples were passed several times through polycarbonate filters (Nucleopore, Pleasanton, CA) of decreasing pore size $(600,200$, and $100 \mathrm{~nm} ; 5,5$ and 10 times, respectively), under inert $\left(\mathrm{N}_{2}\right)$ atmosphere.

Size distribution of extruded vesicles was determined by QELS analysis (Malvern Zeta Sizer 5000, Malvern Instruments, Malvern, Worcestershire, U.K.) using a helium-neon laser (633 $\mathrm{nm})$ as a source of incident light, and operating at a scattering angle of $90^{\circ}$ and at $37{ }^{\circ} \mathrm{C}$. Mean particle size was thus determined as being of $(106 \pm 4) \mathrm{nm}$ (average and standard deviation of six independent measurements). The phospholipid concentration was determined by the phosphomolibdate method. ${ }^{43}$

Preparation of Peptides. Peptides were synthesized as C-terminal carboxamides by Fmoc/tBu solid-phase strategies, purified, and characterized by methods as those described in Gomes et al. ${ }^{44}$ Peptide stock solutions were prepared in HEPES buffer $(10 \mathrm{mM} ; 0.1 \mathrm{M} \mathrm{NaCl} ; \mathrm{pH}=7.4)$ in the $2-5 \mathrm{mM}$ concentration range, and quantitated by either AAA or UV absorption at $280 \mathrm{~nm}$, taking $5690 \mathrm{M}^{-1} \cdot \mathrm{cm}^{-1}$ as the molar 
extinction coefficient, corresponding to the single tryptophan residue present in both peptides.

Differential Scanning Calorimetry. DSC was performed in a microcalorimeter (Micro-DSCIII, SETARAM, Caluire, France) against HEPES buffer in the reference cell. Blank experiments with HEPES buffer on both cells were also performed for subsequent baseline correction. The solution or suspension volume used in each cell was of about $0.8 \mathrm{~mL}$, and the masses of sample and reference cells were adjusted by weight to $\pm 0.00005 \mathrm{~g}$. Two successive up and down scans were performed for each sample, the up scan at a scanning rate of $0.5^{\circ} \mathrm{C} / \mathrm{min}$ and the down scan at $3{ }^{\circ} \mathrm{C} / \mathrm{min}$, over a temperature range of $10-35{ }^{\circ} \mathrm{C}$. The sample mixtures were prepared immediately before the DSC run, by adding the desired amount of peptide stock solution to the LUVs suspension. Separate runs for each liposome suspension without peptide were also done. All procedures regarding sample preparation and handling (lag time at low temperature, time between mixture and start of the experiment) were kept constant in all experiments, to ensure that all samples had the same thermal history. The instrument was electrically calibrated for temperature and scan rate.

The Micro-DSCIII software was used for baseline subtraction, calculation of the gel-to-liquid crystalline phase transition temperature $\left(T_{\mathrm{m}}\right)$, and transition enthalpy $(\Delta H) . T_{\mathrm{m}}$ and $\Delta H$ were calculated by integration of the $C_{p}$ versus temperature curve. For consistency and comparability, the integration was always done between the two points where the curve starts to deviate from and returns to the baseline.

Circular Dichroism. CD measurements were performed in a Jasco 720 spectropolarimeter, with a 175-800 nm photomultiplier (Japan Spectroscopic Co., Tokyo), using a cylindrical cell of $1 \mathrm{~mm}$ path length. Experimental conditions were as follows: $0.5 \mathrm{~nm}$ bandwidth, 50 mdeg sensitivity, $1 \mathrm{~nm}$ resolution, $1 \mathrm{~s}$ time response, discrete wavelength readings $(1 \mathrm{~nm})$. In most cases, each spectrum was the average of six accumulations but, when the signal-to-noise ratio was too low, a higher number (up to 24) of accumulations were used. Buffer runs were repeated throughout the day to check for repeatability. Spectra of pure liposomes at different concentrations were run as blanks to be subtracted from the liposome/peptide spectra. After blank correction, the observed ellipticity was converted to mean residue molar ellipticity $(\theta)\left(\mathrm{deg} \cdot \mathrm{cm}^{2} \cdot \mathrm{dmol}^{-1}\right)$, calculated for the total amount of peptide present in the mixture.

The measurements were done with peptide concentrations ranging from 15 to $75 \mu \mathrm{M}$, and peptides were added to the lipid suspensions immediately before measurement. All spectra were recorded at $25{ }^{\circ} \mathrm{C}$, unless otherwise indicated.

The interaction with DMPC was found to be a slow process, taking about half an hour to stabilize the CD signal, after which the reported spectra were recorded. This behavior was not observed with DMPG.

Quasi-Elastic Light Scattering. The zeta-potential and vesicle diameter were determined by QELS analysis (Malvern Zeta Sizer 5000, Malvern Instruments, Malvern, Worcestershire, U.K.). The measurements were performed in a ZET 5104 cell, at a temperature of $37^{\circ} \mathrm{C}$ and a scattering angle of $90^{\circ}$. The viscosity and refractive index values were $0.662 \mathrm{cP}$ and 1.330 , respectively.

The reference values for zeta potential and vesicle diameters were obtained from measurements with the three pure lipid systems: DMPC, DMPG, and DMPC/DMPG (3:1). The appropriate amounts of peptide stock solutions were then added to the respective liposome suspension in order to obtain the desired peptide-to-lipid (P:L) molar ratios (1:100, 1:50, and
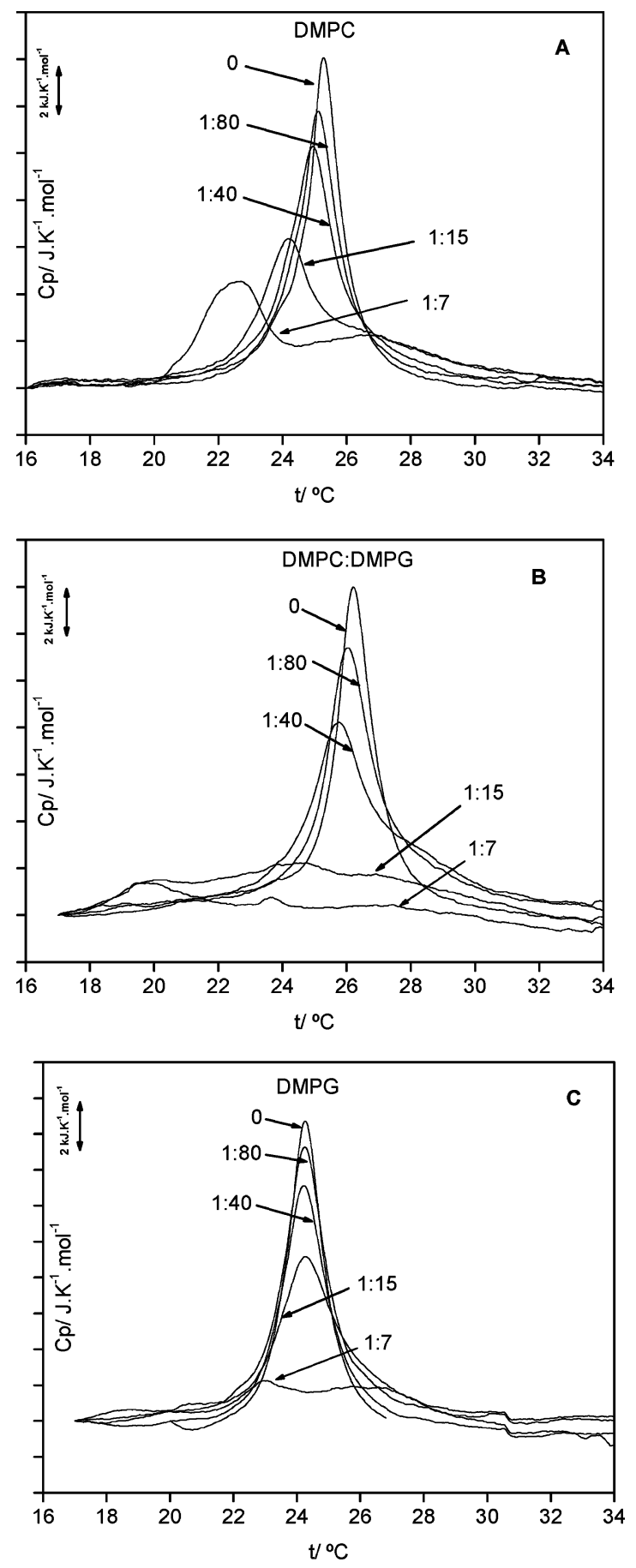

Figure 2. DSC curves obtained for liposomes and $\mathrm{CA}(1-8) \mathrm{M}(1-$ 18) for different peptide-to-lipid molar ratios: DMPC (A); DMPC/ DMPG 3:1 (B); DMPG (C). The molar ratio (P:L) for each profile is indicated in the figure. Lipid concentration was $2.6 \pm 0.3 \mathrm{mM}$ in all experiments.

1:20). Due to precipitation observed for the higher P:L ratios in the charged lipid systems, the samples were centrifuged (700 rpm, 20-45 $\mathrm{min}$ ) prior to measurements on the supernatant.

\section{Results}

Calorimetry. Endotherms obtained for each peptide with the different lipid systems are shown in Figures 2 and 3. The calculated thermodynamic parameters are listed in Table 2, where values for the pure lipid systems are also shown. The small differences in $T_{\mathrm{m}}$ and $\Delta H$, observed for the same pure lipid system, were not significant within the experimental error. 

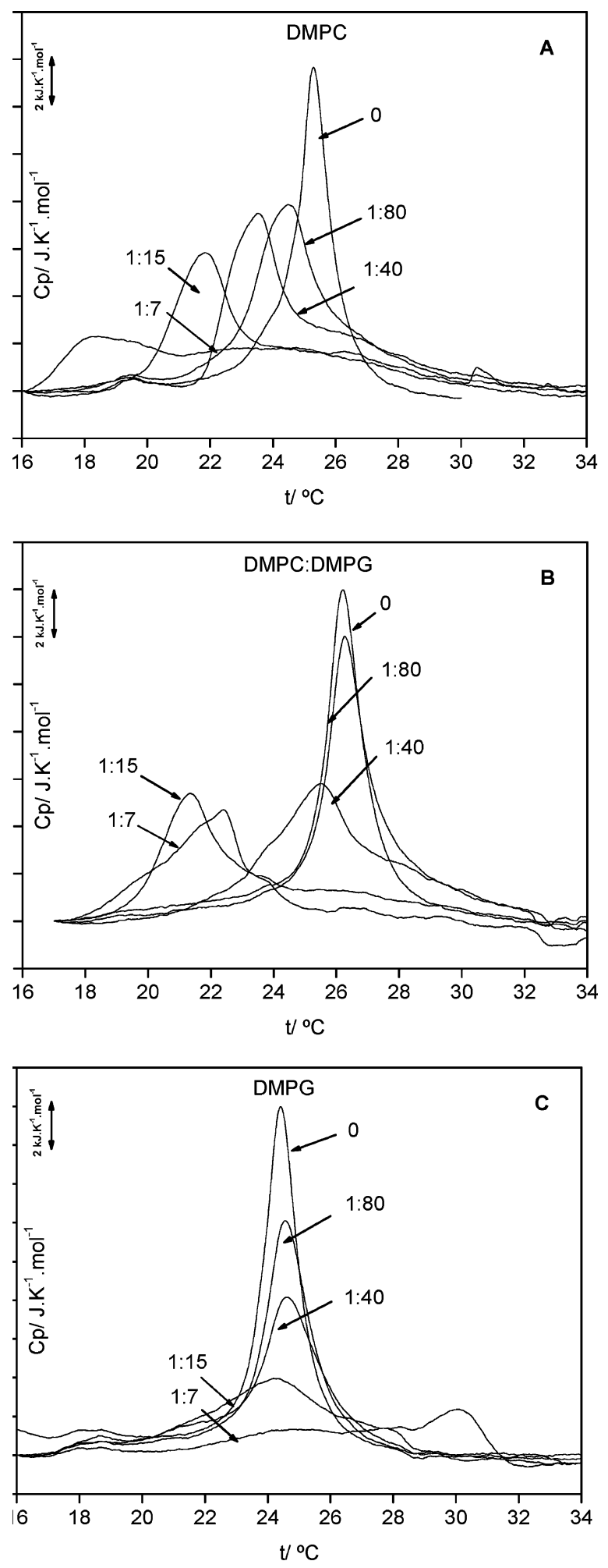

Figure 3. DSC curves obtained for liposomes and CA(1-7)M(2-9) for different peptide to lipid molar ratios: DMPC (A); DMPC/DMPG 3:1 (B); DMPG (C). The molar ratio (P:L) for each profile is indicated in the figure. Lipid concentration was $2.6 \pm 0.3 \mathrm{mM}$ in all experiments.

Nevertheless, measurements on the same peptide/lipid systems were always done using the same liposome suspension, to avoid slight differences that might arise from different lipid samples.

The calorimetric profile for the pure lipid systems was a symmetric and highly cooperative peak. For pure DMPC (Figures $2 \mathrm{~A}$ and $3 \mathrm{~A}$ ), the phase transition occurred at $25.3{ }^{\circ} \mathrm{C}$ with an enthalpy of 23.8 or $22.5 \mathrm{~kJ} \cdot \mathrm{mol}^{-1}$ (Table 2). As the
TABLE 2: Transition Temperatures, $T_{\mathrm{m}}$, and Enthalpy Change Values, $\Delta H$, as a Function of Peptide-to-Lipid Molar Ratio (P:L) for the Three Lipid Systems and Both Peptides ${ }^{a}$

\begin{tabular}{lllccc}
\hline & \multirow{2}{*}{$\begin{array}{c}\mathrm{P}: \mathrm{L} \\
\text { lipid system }\end{array}$} & \multicolumn{2}{c}{$\mathrm{CA}(1-8) \mathrm{M}(1-18)$} & \multicolumn{2}{c}{$\mathrm{CA}(1-7) \mathrm{M}(2-9)$} \\
\cline { 3 - 5 } \cline { 5 - 6 } DMPC & 0 & 25.3 & 23.8 & 25.3 & 22.5 \\
& $1: 80$ & 25.1 & 22.8 & 24.5 & 23.3 \\
& $1: 40$ & 24.9 & 22.8 & 23.5 & 22.4 \\
& $1: 15$ & 24.2 & 22.2 & 21.9 & 22.3 \\
& $1: 7$ & $22.3 / 26.4$ & 21.7 & 18.4 & 20.8 \\
DMPC:DMPG & 0 & 26.2 & 28.4 & 26.2 & 28.4 \\
& $1: 80$ & 26.0 & 28.5 & 26.3 & 27.6 \\
& $1: 40$ & 25.8 & 27.3 & 25.5 & 28.0 \\
& $1: 15$ & 24.8 & 21.2 & 21.3 & 21.7 \\
DMPG & $1: 7$ & 19.8 & 13.7 & 22.4 & 20.4 \\
& 0 & 24.3 & 28.0 & 24.5 & 25.8 \\
& $1: 80$ & 24.3 & 29.1 & 24.6 & 24.4 \\
& $1: 40$ & 24.2 & 24.3 & 24.6 & 24.4 \\
& $1: 15$ & 24.3 & 20.0 & 24.0 & 21.1 \\
& $1: 7$ & $23.0 / 25.8$ & 16.5 & 30.0 & 15.3
\end{tabular}

${ }^{a}$ The reported enthalpy corresponds to the total peak area (see text). The estimated uncertainty in $T_{\mathrm{m}}$ is $\pm 0.3{ }^{\circ} \mathrm{C}$ and in $\Delta H$ it is \pm 0.5 $\mathrm{kJ} \cdot \mathrm{mol}^{-1}$ (for the same liposome suspension) and $\pm 3 \mathrm{~kJ} \cdot \mathrm{mol}^{-1}$ (within samples). $\mathrm{P}: \mathrm{L}$ ratio is molar ratio.

concentration of $\mathrm{CA}(1-8) \mathrm{M}(1-18)$ was increased, up to a $\mathrm{P}: \mathrm{L}$ ratio of 1:40 (Figure 2A), the transition temperature slightly and gradually decreased. The cooperativity of the transition also decreased, but the symmetry of the peak was kept, suggesting that there was only a small perturbation, probably due to the interaction at the level of the phospholipid headgroups. For the higher P:L ratios, the transition temperature fell significantly, although the overall enthalpy was still only slightly affected. The profile showed further decrease in cooperativity, with further broadening of the peak and the appearance of a shoulder at higher temperatures. At the highest P:L ratio used, the shoulder evolved into two different domains (see Figure 2A), characterized by two distinct peak maxima, one at a lower (22.3 $\left.{ }^{\circ} \mathrm{C}\right)$ and the other at a higher $\left(26.4{ }^{\circ} \mathrm{C}\right)$ temperature than $T_{\mathrm{m}}$. Overall, the enthalpy values showed a decrease of no more than $2 \mathrm{~kJ} \cdot \mathrm{mol}^{-1}$ across the range of $\mathrm{P}: \mathrm{L}$ ratios employed.

In contrast, the smaller $\mathrm{CA}(1-7) \mathrm{M}(2-9)$ peptide largely decreased $T_{\mathrm{m}}$, even at the lower P:L ratios (Figure $3 \mathrm{~A}$ ). The cooperativity of the transition was also affected at all peptide concentrations. As observed with $\mathrm{CA}(1-8) \mathrm{M}(1-18)$, the enthalpy was not significantly altered, except at the highest P:L ratio (1:7), where only a very broad transition was detected.

Therefore, both peptides promoted a decrease in $T_{\mathrm{m}}$ and in the cooperativity of the transition, and these effects were more pronounced for $\mathrm{CA}(1-7) \mathrm{M}(2-9)$.

In the anionic DMPG system (Figures 2C and 3C), both peptides had similar behavior up to a P:L ratio of 1:40. $T_{\mathrm{m}}$ was approximately constant at all P:L ratios, but the profiles of the two peptides diverged above 1:40.

At $P: L$ values of $1: 15$, the profile for $C A(1-7) \mathrm{M}(2-9)$ was already a superimposition of two broad peaks, one still centered at about $24{ }^{\circ} \mathrm{C}$ and the other at ca. $28{ }^{\circ} \mathrm{C}$. At the highest P:L ratio (1:7), a very distorted profile and a marked decrease in $\Delta H$ were observed

$\mathrm{CA}(1-8) \mathrm{M}(1-18)$ caused only a very slight peak asymmetry at the P:L ratio of 1:15 (a small shoulder at higher temperatures). However, the profile became totally distorted at a P:L ratio of 1:7, with two peaks at 23.0 and $25.8^{\circ} \mathrm{C}$. Further, at a P:L ratio as low as $1: 40, \Delta H$ values were significantly decreased, whereas the cooperativity of the transition was only slightly affected.

Measurements with the DMPC/DMPG mixed system (Figures $2 \mathrm{~B}$ and $3 \mathrm{~B}$ ) yielded results that lay between those described 
above for the two pure DMPC and DMPG systems. Up to a $\mathrm{P}: \mathrm{L}$ ratio of $1: 80, T_{\mathrm{m}}$ and $\Delta H$ were not affected and the thermograms were similar to those observed for the anionic DMPG system. Further increase in peptide concentration led to a decrease in both $T_{\mathrm{m}}$ and $\Delta H$, and this effect was more pronounced for peptide $\mathrm{CA}(1-7) \mathrm{M}(2-9)$. For this peptide, the decrease in $T_{\mathrm{m}}$ was similar to that observed with pure DMPC, whereas the decrease in $\Delta H$ was parallel to that observed for pure DMPG.

Analysis of the profiles displayed in Figures 2B and 2C shows that the effect caused by peptide $\mathrm{CA}(1-8) \mathrm{M}(1-18)$ at $\mathrm{P}: \mathrm{L}$ ratios of $1: 15$, and above, was comparable to that observed with the DMPG system at higher peptide concentrations.

Circular Dichroism. The secondary structures of CA(17) $\mathrm{M}(2-9)$ and $\mathrm{CA}(1-8) \mathrm{M}(1-18)$ were examined by $\mathrm{CD}$ in HEPES buffer and in the presence of the three liposome systems. Measurements of peptide solutions within the $15-50 \mu \mathrm{M}$ concentration range showed that peptide structures did not apparently change in that interval, thus only one concentration $(38 \mu \mathrm{M})$ is plotted for each peptide (Figure 4). CD spectra of both peptides in the presence of DMPC, DMPG, and DMPC/ DMPG (3:1) liposomes are displayed in Figure 4.

CD measurements were also done on peptide solutions containing $50 \%(\mathrm{v} / \mathrm{v})$ trifluorethanol (TFE), to evaluate peptide propensity to adopt an $\alpha$-helical conformation and to compare data thus obtained with previous reports. Both peptides displayed a predominant $\alpha$-helical structure in the presence of TFE, more pronounced for $\mathrm{CA}(1-7) \mathrm{M}(2-9)(79 \% \alpha$-helix, $0 \% \beta$-sheet and $21 \%$ random coil) than for $\mathrm{CA}(1-8) \mathrm{M}(1-18)(48 \% \alpha$-helix, $22 \% \beta$-sheet and $30 \%$ random coil). These values were obtained by fitting the mean residue molar ellipticities of each peptide under the linear sum approach proposed by Chen et al. ${ }^{45}$ Best fittings were obtained by employment of the mean residue molar ellipticities provided by Greenfield and Fasman for synthetic polypeptides. ${ }^{46}$ Results are in good agreement with those previously reported for these peptides under similar conditions (HFIP $12 \%$ (v/v) in buffer). ${ }^{8,47}$

Spectra showed that $\mathrm{CA}(1-7) \mathrm{M}(2-9)$ adopted a randomcoil structure in buffer, characterized by a minimum at $\sim 198$ $\mathrm{nm}$. In the presence of DMPC liposomes (Figure 4A), there was a gradual red shift of the $\lambda_{\max }$ of this negative band, which increased with lipid concentration. A maximum negative ellipticity at about $208 \mathrm{~nm}$ was observed when the lipid concentration was $1200 \mu \mathrm{M}(\mathrm{P}: \mathrm{L}$ ratio $=1: 33)$, typical of the presence of an $\alpha$-helix. This effect was less marked when the P:L ratio was increased to 1:20, at a lower lipid concentration $(800 \mu \mathrm{M})$.

In the presence of DMPG liposomes, peptide CA(1-7)M(2-9) structure suffered a clear conformational change to an $\alpha$-helix (Figure 4E), with the typical maximum negative ellipticities at 208 and $222 \mathrm{~nm}$. Employment of different P:L ratios (1:30 and 1:20) for the same lipid concentration (1200 $\mu \mathrm{M})$ did not introduce significant changes in spectra, showing that the mean residual ellipticities were almost independent of the $\mathrm{P}: \mathrm{L}$ ratio.

CA(1-8)M(1-18) spectra showed maxima at 198-202 nm and minima at $214-219 \mathrm{~nm}$, which were strongly indicative of a $\beta$-sheet structure (parts B, D, and F of Figure 4). The strong minimum observed at $228-230 \mathrm{~nm}$ was probably due to the tryptophan residue, arising from $\mathrm{B}_{\mathrm{b}}$ band absorbance of the indole side chain when in aggregate state. ${ }^{19}$ Fitting $\mathrm{CD}$ data for this peptide in buffer led to $0 \% \alpha$-helix, $55 \% \beta$-sheet, and $45 \%$ random coil, in perfect agreement with a previous report by Wade et al. ${ }^{44}$ In the presence of DMPC (Figure 4B), an $\alpha$-helical structure was only evident at the highest lipid concentration
$(6000 \mu \mathrm{M})$, even when the P:L ratio was as low as $1: 200$. The insert in Figure 4D corresponds to an assay run at $30{ }^{\circ} \mathrm{C}$ (well above $T_{\mathrm{m}}$ ) using the same peptide and lipid concentrations and shows a much better defined $\alpha$-helix, with stronger negative ellipticity at $208 \mathrm{~nm}$.

In the presence of charged liposomes (Figure 4F), CA(18) $\mathrm{M}(1-18)$ showed an $\alpha$-helical structure at a lipid concentration of $3000 \mu \mathrm{M}$, which was half of that required to observe a similar effect with DMPC. Spectra obtained at lower lipid concentrations did not display such clearly defined minima and suggest that substantial $\beta$-sheet content remained present (results not shown). In all DMPG/CA(1-8)M(1-18) mixtures, aggregation was visually detected immediately after mixing. After a DMPG/CA(1-8)M(1-18) mixture was centrifuged (P:L ratio $=1: 140)$, the CD spectrum of the supernatant showed that the nonagreggated fraction still displayed an $\alpha$-helical structure.

CD spectra of samples containing the DMPC/DMPG mixed liposomes clearly showed the presence of helical conformations for both peptides, which were already evident at low P:L ratios and high lipid concentrations (Figure 4C,D). For CA(1-8)M$(1-18)$, the presence of an $\alpha$-helix was already clear at a lipid concentration of $1200 \mu \mathrm{M}$, a value smaller than that required to observe the same behavior with pure DMPG.

Quasi-Elastic Light Scattering. Values of particle diameter and zeta potential obtained by QELS are presented in Table 3 for the three lipid systems, at different P:L ratios. Both peptides influence the behavior of DMPC vesicles in a similar manner: vesicle size was almost constant at all P:L ratios, whereas zeta potentials increase along with $\mathrm{P}: \mathrm{L}$ ratios.

A larger polydispersion was observed for DMPG vesicles at all peptide concentrations, suggesting a more heterogeneous system. Some experiments ( $\mathrm{P}: \mathrm{L} \geq 1: 50$ ) involving DMPG required a previous centrifugation step, as massive aggregation/ precipitation promptly took place after peptide addition to the lipid suspension, with formation of large particles. In some cases, the presence of two distinct and significant populations could be detected even after centrifugation.

For $\mathrm{CA}(1-7) \mathrm{M}(2-9)$ at $\mathrm{P}: \mathrm{L}=1: 100$, two main populations were observed, with diameters of 107 and 489 nm. For P:L ratios of $1: 50$ and $1: 20$, the population with $120-130 \mathrm{~nm}$ diameters became predominant but, at a 1:20 ratio, a population of diameter of $\sim 1084 \mathrm{~nm}$ remained detectable even after centrifugation.

When CA $(1-8) \mathrm{M}(1-18)$ was added to DMPG at high P:L ratios, only a single population was observed after centrifugation. This population had a diameter larger than that for pure DMPG but similar to the diameter observed at a lower P:L ratio (1: 100) without centrifugation. Thus, the centrifugation step led to the removal of very large aggregates from the supernatant that was subsequently analyzed.

For both peptides, zeta potentials became less negative upon peptide addition to DMPG, although this change was not as pronounced as that observed with the zwitterionic DMPC system.

Results obtained with the DMPC/DMPG liposomes provided evidence, again, of an intermediate behavior. Particle size gradually increased with P:L ratio up to the value of 1:20, at which centrifugation was required. The zeta potentials were also changed by addition of both peptides, but with distinct features. Peptide CA(1-7)M(2-9) caused a gradual zeta potential increase with $\mathrm{P}: \mathrm{L}$ ratio, whereas only at $\mathrm{P}: \mathrm{L}=1: 100$ did CA$(1-8) \mathrm{M}(1-18)$ provoke an evident change in zeta potential, which remained constant thereafter. 


\section{$\mathrm{CA}(1-7) \mathrm{M}(2-9)$}
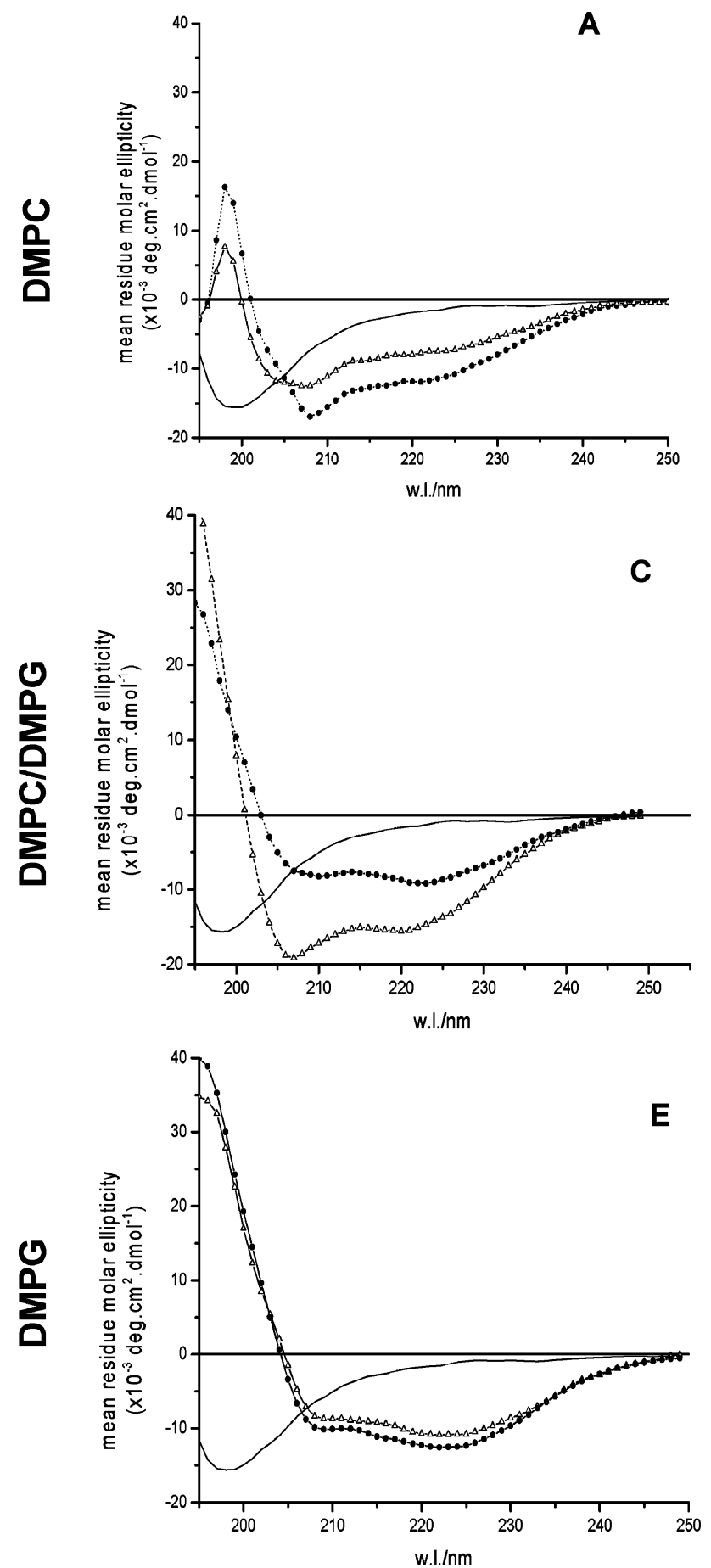

$\mathrm{CA}(1-8) \mathrm{M}(1-18)$
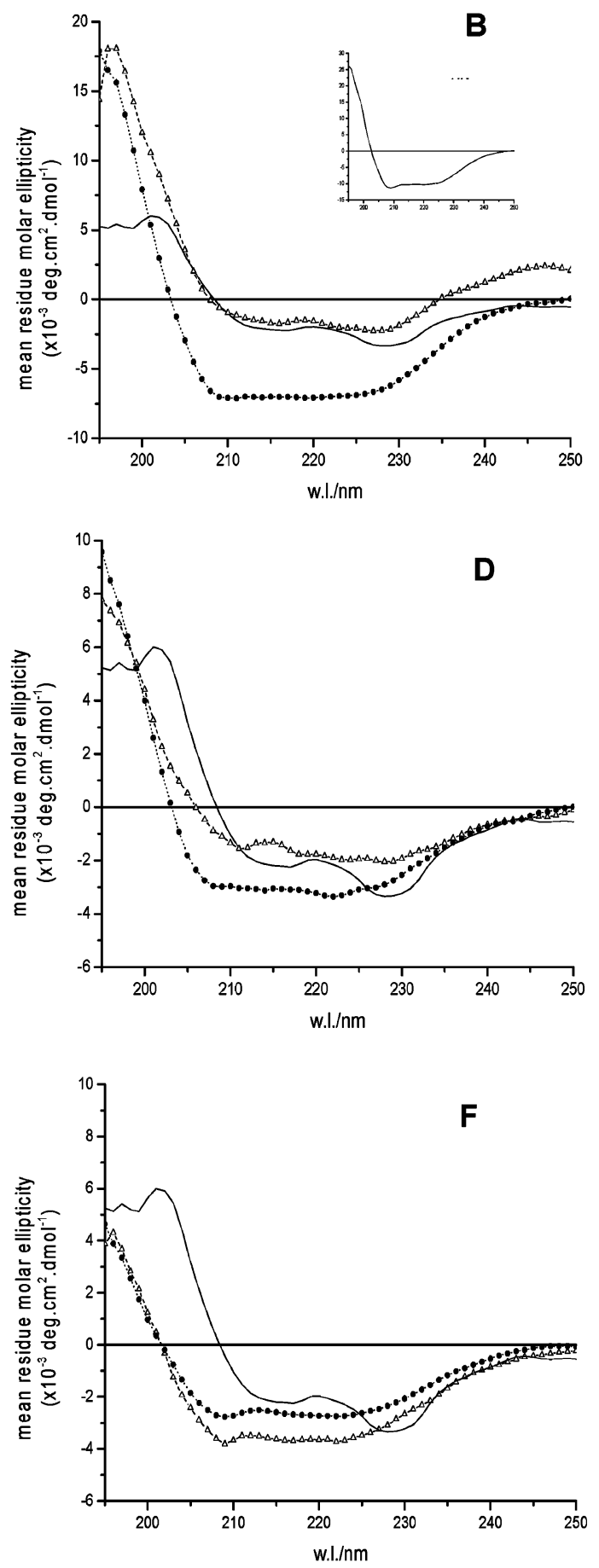

Figure 4. CD spectra $\left(T \sim 25^{\circ} \mathrm{C}\right)$ of $\mathrm{CA}(1-8) \mathrm{M}(1-18)$ and $\mathrm{CA}(1-7) \mathrm{M}(2-9) 38 \mu \mathrm{M}$ in aqueous buffer (solid lines), and in the presence of LUVs of DMPC (A, B), DMPC/DMPG 3:1 (C, D), and DMPG (E, F). The lipid concentrations and P:L ratios are as follows: DMPC (A) 800 $\mu$ M, 1:20 $(\triangle), 1200 \mu \mathrm{M}, 1: 30(\bullet)$; (B) $1500 \mu \mathrm{M}, 1: 50(\triangle), 6000 \mu \mathrm{M}, 1: 200(\bullet)$; DMPC/DMPG (C) $800 \mu \mathrm{M}, 1: 20(\bullet), 1200 \mu \mathrm{M}, 1: 30(\triangle)$; (D) $800 \mu \mathrm{M}, 1: 30$ $(\triangle), 1200 \mu \mathrm{M}, 1: 30(\bullet)$; DMPG (E) $1200 \mu \mathrm{M}, 1: 30(\triangle), 1200 \mu \mathrm{M}, 1: 20(\bullet)$; (F) $3000 \mu \mathrm{M}, 1: 40(\triangle), 3000 \mu \mathrm{M}, 1: 70(\bullet)$. The insert in part B corresponds to the CD spectrum of $\mathrm{CA}(1-8) \mathrm{M}(1-18)(38 \mu \mathrm{M})$ in the presence of DMPC $(6000 \mu \mathrm{M})$ at $30{ }^{\circ} \mathrm{C}$.

\section{Discussion}

The biological activity of antimicrobial peptides has been largely associated to their interaction with membranes. Several key factors have been shown to be associated with this interaction, depending on both peptide and membrane composition.

The results described above, for the interactions of peptides $\mathrm{CA}(1-7) \mathrm{M}(2-9)$ and $\mathrm{CA}(1-8) \mathrm{M}(1-18)$ with three lipid bi- layer systems, allow us to shed some light onto the peptidemembrane interactions that may possibly underlie the mechanisms of peptide antimicrobial action.

Interaction with DMPC Membranes. Both peptides interact with zwitterionic DMPC membranes, although to different extents. Overall, the changes observed in the DSC profiles, as well as in $T_{\mathrm{m}}$ and $\Delta H$, are similar. This was also observed from QELS analysis, where variations in particle size and zeta 
TABLE 3: Values for Liposome Size and Zeta Potential as a Function of Peptide-to-Lipid Molar Ratio (P:L) for the Three Lipid Systems and Both Peptides ${ }^{a}$

\begin{tabular}{|c|c|c|c|c|c|}
\hline \multirow[b]{2}{*}{ lipid } & \multirow[b]{2}{*}{$\begin{array}{l}\mathrm{P}: \mathrm{L} \\
\text { ratio }\end{array}$} & \multicolumn{2}{|c|}{$\mathrm{CA}(1-7) \mathrm{M}(2-9)$} & \multicolumn{2}{|c|}{$\mathrm{CA}(1-8) \mathrm{M}(1-18)$} \\
\hline & & size/nm & $\begin{array}{c}\text { zeta } \\
\text { potential/ } \\
\mathrm{mV}\end{array}$ & size/nm & $\begin{array}{c}\text { zeta } \\
\text { potential/ } \\
\mathrm{mV}\end{array}$ \\
\hline \multirow{4}{*}{ DMPC } & 0 & 108 & -6.6 & 108 & -6.6 \\
\hline & $1: 100$ & 112 & 7.5 & 112 & 6.4 \\
\hline & $1: 50$ & 112 & 7.2 & 111 & 8.4 \\
\hline & $1: 20$ & 117 & 13.3 & 112 & 13.3 \\
\hline \multirow{4}{*}{ DMPG } & 0 & 105 & -54.7 & 105 & -54.7 \\
\hline & $1: 100$ & $107 / 489$ & -47.0 & 125 & -41.1 \\
\hline & $1: 50$ & 125 & -48.2 & 126 & -36.7 \\
\hline & $1: 20$ & $121 / 1084$ & -35.1 & 137 & -44.2 \\
\hline \multirow{4}{*}{ DMPC:DMPG } & 0 & 107 & -32.5 & 107 & -32.5 \\
\hline & $1: 100$ & 114 & -23.9 & 111 & -24.3 \\
\hline & $1: 50$ & 117 & -17.2 & 120 & -27.5 \\
\hline & $1: 20$ & 128 & 7.1 & 141 & -25.6 \\
\hline
\end{tabular}

${ }^{a}$ The values in boldface type correspond to measurements in the supernatant.

potential were parallel for both peptides. The zeta potential increase with P:L ratio indicates that liposomes get an increasingly positive charge, which is compatible with a progressive surface coverage of the zwitterionic membranes. Calculations by Zuckermann and Heimburg ${ }^{48}$ indicate that each interfacially adsorbed peptide covers about seven lipids. The highest P:L ratio used in QELS experiments was 1:20, which is still below full coverage; thus the continuous increase in zeta potential is compatible with surface adsorption. This is supported by the broadening of the DSC curves and the decrease in $T_{\mathrm{m}}$ that is compatible with a better interaction of the peptide with the liquid crystalline phase of DMPC. As shown by other authors, ${ }^{27,49-52}$ surface insertion leads to bilayer thinning and induces an increase in local negative curvature, which explains both the lowering of $T_{\mathrm{m}}$ and the broadening of DSC curves.

The decrease in $T_{\mathrm{m}}$ with increasing P:L ratio is more pronounced for the $\mathrm{CA}(1-7) \mathrm{M}(2-9)$ peptide, and the cooperativity of the transition rapidly falls, even for low P:L ratios. The DSC profile exhibits a shoulder at higher temperatures with increasing peptide concentration, and an extremely broad transition of lower $\Delta H$ is observed at a P:L ratio of 1:7 (Table 2, Figure $3 \mathrm{~A})$. For the same range of $\mathrm{P}: \mathrm{L}$ ratios, a smaller decrease in $T_{\mathrm{m}}$ is caused by CA $(1-8) \mathrm{M}(1-18)$ and curve shape does not change as dramatically as in the case of CA(1-7)M(2-9). At the highest P:L ratio, two domains become apparent, although the total $\Delta H$ value remains unaltered. This is supported by $\mathrm{CD}$ analysis, which indicates that $\mathrm{CA}(1-8) \mathrm{M}(1-18)$ has a much lower lipid-water partition to zwitterionic membranes than $\mathrm{CA}(1-7) \mathrm{M}(2-9)$ (Figure 4). Nevertheless, the approximately constant $\Delta H$ values, observed with both peptides even at very high $\mathrm{P}: \mathrm{L}$ ratios, indicate that they do not drastically perturb the hydrocarbon chain packing of DMPC, as the enthalpy for the main transition is primarily due to the disruption of intra- and intermolecular van der Waals interactions that leads to chain melting. These results thus suggest that the peptides do not penetrate too deeply into the bilayer, except at the highest $\mathrm{P}: \mathrm{L}$ ratios. A recent site-directed spin-labeling study of CA$(1-7) \mathrm{M}(2-9)$ reported that, at low concentration of bound peptide, it intercalates into the DMPC membrane just below the bilayer surface, adopting an $\alpha$-helical conformation with the helix axis parallel to the membrane surface. ${ }^{53}$ According to these authors, this peptide orientation allows the hydrophobic face of the helix to be buried in the hydrophobic phase of the bilayer, whereas the hydrophilic residues are near the membrane- water interface. These results were obtained at P:L ratios up to 1:125 and are fully compatible with our data for all but the highest P:L ratio.

The formation of different domains, as observed with CA$(1-8) \mathrm{M}(1-18)$, has already been reported for different lipid and peptide systems ${ }^{16,28,35,54}$ and is consistent with a lower compatibility of this peptide with DMPC, which is also supported by our CD and QELS experiments. The appearance of shoulders in thermograms is a consequence of a nonideal mixing behavior, which creates a nonhomogeneous distribution of the peptide within the membrane. ${ }^{50,52}$ Thus, regions richer in peptide can eventually lead to the formation of two different coexisting phases. Our DSC results for CA(1-8) $\mathrm{M}(1-18) /$ DMPC mixtures are compatible with such events, particularly at higher peptide ratios, where two broad transitions can be observed, each probably corresponding to a different coexisting phase.

It has been reported that the parent cecropin A peptide forms an $\alpha$-helix with the longitudinal axis coplanar with the membrane, ${ }^{21,23}$ and the carpet model was suggested for the interaction of cecropins with phospholipid bilayers. ${ }^{55}$ The initial phase in this model is, in fact, equivalent to the physical structure described by the "S" state in the two-state model by Huang. ${ }^{22}$ As for Melittin, Yang et al. ${ }^{25}$ suggested that their results were compatible with the toroidal model for the interaction with zwitterionic membranes. These authors have also observed an increase in negative surface curvature due to membrane thinning, which they considered consistent with the initial requirements for the formation of a toroidal pore. ${ }^{22,56}$ This interpretation is fully compatible with our results and, taken together, our DSC and QELS data indicate that membrane insertion would probably occur only at P:L ratios higher than 1:20.

Interaction with DMPG Membranes. The effect of both peptides on the thermotropic phase behavior of DMPG is very different from the one observed with the zwitterionic system (Figures 2C and 3C). Basically, for small peptide amounts, neither the transition enthalpy nor its cooperativity are seriously affected. For P:L ratios higher than 1:40, $\Delta H$ is significantly decreased. The main difference between the two peptides is that the cooperativity of the transition is affected at lower $\mathrm{P}: \mathrm{L}$ ratios for $\mathrm{CA}(1-7) \mathrm{M}(2-9)$ than for $\mathrm{CA}(1-8) \mathrm{M}(1-18)$. A possible explanation for this difference is that $\mathrm{CA}(1-7) \mathrm{M}(2-9)$ also has a higher lipid-water partition in $\alpha$-helical form to negatively charged membranes. This interpretation is supported by our CD data, as no changes in spectra were observed for CA(1-7)M$(2-9) / D M P G$ when the P:L ratio was varied from 1:30 to $1: 20$ at the same lipid concentration.

Light scattering analysis showed that, upon addition of CA$(1-7) \mathrm{M}(2-9)$ to DMPG, differently sized populations are present even after centrifugation (Table 3). In contrast, after addition of $\mathrm{CA}(1-8) \mathrm{M}(1-18)$ to DMPG and centrifugation, the population that remains in the supernatant has only a slightly higher average diameter at the highest P:L ratio. Zeta potential values (Table 3) are approximately constant at all P:L ratios (complete system and supernatant), decreasing about $10 \mathrm{mV}$ as compared to the pure liposome system. This small variation should be regarded as a mere fluctuation, as it is smaller than one would predict if a simple partition equilibrium was taking place.

The joint interpretation of all these data suggests a different mechanism for the interactions between the $\mathrm{CA}-\mathrm{M}$ hybrid peptides and negatively charged membranes. Up to a threshold concentration, both peptides adopt a helical conformation and are located at the membrane surface, therefore affecting only 
slightly $T_{\mathrm{m}}, \Delta H$, and the cooperativity of the thermotropic phase transition. Moreover, the average liposome diameter increases and the negative potential close to the surface decreases upon peptide addition. Above the threshold concentration (P:L higher than 1:100), massive aggregation/precipitation is observed, and peak splitting in the corresponding DSC profiles suggests the possible presence of distinct lipid-peptide aggregates. The decrease in $\Delta H$, with no significant changes in either $T_{\mathrm{m}}$ or cooperativity, can be interpreted as the outcome of two distinct populations: (i) liposomes slightly disturbed by a small amount of surface bound helical peptide, yielding a DSC profile very similar to the pure lipid system, and (ii) aggregated bilayers, intercalated with helical peptides that are strongly bound to the surface of the negatively charged liposomes, mainly by electrostatic attraction. The thermotropic phase transition of these aggregates must be of low enthalpy and too broad to be resolved with the sensitivity of our DSC instrument. This leads, therefore, to a small global $\Delta H$ value. At the highest P:L ratio it shows up as a very broad (or two broad) transition, with further decrease in overall $\Delta H$, as its relative importance increases. The apparent insensitivity of zeta potential values toward the P:L ratio supports this interpretation, as for the higher 1:50 and 1:20 $\mathrm{P}: \mathrm{L}$ ratios the remaining liposome/peptide aggregates precipitated and were removed by centrifugation. Data from the three techniques used are all fully compatible with our hypothesis that the interaction mechanism must be common for both peptides, with a stronger membrane disrupting effect for CA$(1-8) \mathrm{M}(1-18)$, as larger aggregate particles are formed and the process is visually faster.

Although a detailed description of the mechanism requires other types of experimental evidence, some additional comments can be made at this stage. Both peptides have a large positive charge ( +5 at the $\mathrm{pH}$ employed), and therefore the interaction with negatively charged membranes must be strong and have a significant electrostatic component. This would preclude a transmembrane insertion according to a barrel-stave model, but not as a toroidal pore. Nevertheless, the extensive precipitation that occurs with DMPG at P:L ratios higher than 1:100, when mixtures were prepared at $\sim 22{ }^{\circ} \mathrm{C}$ (below $T_{\mathrm{m}}$ ), was difficult to reconcile with the toroidal pore model. Recently, Ladokhin and White $^{49}$ addressed the problem of the different interaction profiles of melittin with zwitterionic versus anionic membranes, to understand why anionic lipids decrease the ability of melittin to permeabilize zwitterionic liposomes. These authors suggest that melittin cannot adopt a trans-membrane configuration when bound to anionic liposomes and that the known permeabilization of negatively charged membranes by melittin is possibly due to a mechanism of "leaky" fusion. This was supported by their observation of increased scattering upon addition of melittin to POPG. Lafleur et al. ${ }^{57}$ studied a similar system by Raman spectroscopy, suggesting a model where, in the gel phase, melittin tetramers bridge two adjacent bilayers of the anionic lipid, causing precipitation of the complex. Madeira et al. ${ }^{58}$ have also reported a similar mechanism for the interaction of DNA with oppositely charged liposomes, and Dias et al. ${ }^{59}$ also found strong associative phase behavior for interactions of DNA with catanionic vesicles, with formation of precipitates. We expect these cecropin A-melittin hybrid peptides to interact with DMPG in a similar manner, as it provides a sensible explanation that is consistent with all our experimental findings.

Interaction with DMPC/DMPG Membranes. The results obtained for the mixed DMPC/DMPG lipid system, with the three techniques employed, correspond to an intermediate situation. This emphasizes the importance of the phospholipid headgroups and related electrostatic effects to the interaction between both cecropin $\mathrm{A}-$ melittin cationic peptides and lipid membranes. Data in Table 3 show that, for a P:L ratio of 1:100, the variation in size and zeta potential is similar to that observed for the zwitterionic system, whereas at 1:50 and 1:20 P:L ratios, the variation of these parameters suggests an interaction similar to the one observed for DMPG at higher peptide concentrations. This must arise from a preferential interaction with the charged lipids in the mixed system, leading to higher local peptide concentrations in the negatively charged membrane regions. This phenomenon would produce an effect equivalent to that observed in DMPG, but at an apparently lower total concentration.

CD spectra (parts C and D of Figure 4) clearly show that the mixed lipid system induces both peptides to acquire an $\alpha$-helical structure already at low $\mathrm{P}: \mathrm{L}$ ratio, and the effect of $\mathrm{P}: \mathrm{L}$ ratio is larger with this system. This must, again, be due to a preferential location of the peptides on anionic regions of the mixed membrane. The zwitterionic lipids of the mixed system help to avoid extensive aggregation, allowing the $\alpha$-helix to be observed at lower lipid concentrations.

As a final note to this discussion, we would like to stress that $\mathrm{CA}(1-8) \mathrm{M}(1-18)$ adopts mainly a $\beta$-sheet structure in buffer, possibly antiparallel (Figure 4 ), which probably allows for a better shielding of the more hydrophobic amino acids (Figure 1). Therefore, the energy balance in the process of destroying the $\beta$-sheet structure plus forming an $\alpha$-helix upon membrane interaction may be less favored, in comparison to the partition of $\mathrm{CA}(1-7) \mathrm{M}(2-9)$ from random coil to an $\alpha$-helix in the membrane. In fact, by simply raising the temperature above $T_{\mathrm{m}}$ in a CD assay with CA(1-8)M(1-18)/DMPC, a much better defined $\alpha$-helix could be observed (insert in Figure 4B). This is compatible with a higher partition of the helical form to the fluid phase and a decrease in $\beta$-sheet content with increasing temperature, as previously observed by Wimley et al. ${ }^{19}$

\section{Concluding Remarks}

The present study aimed at the establishment of a correlation between peptide-induced modifications on differently charged membranes and membrane-induced changes in peptide secondary structure. The antimicrobial peptides studied are known to adopt an $\alpha$-helical structure in the presence of membranes. ${ }^{15,21,23,25,60}$ The importance of this structure for antimicrobial activity has been a subject of debate, whereas the influence of membrane charge on peptide-membrane interaction is relevant for the development of selective antibiotics. $5,20,30,49,61$

From the present work, we can conclude that DSC provided a detailed insight into - and differentiation between - the interactions of two cecropin A-melittin hybrid peptides with three lipid model systems. CD and light scattering data complemented the DSC study, allowing altogether the proposal of two different mechanisms for peptide-membrane interactions, dictated by membrane charge. Further, it was possible to distinguish, for each membrane system, the slightly different behaviors of the two antimicrobial peptides under study. In fact, although the shorter $\mathrm{CA}(1-7) \mathrm{M}(2-9)$ peptide is known to retain most of the antimicrobial activity of its larger $\mathrm{CA}(1-8) \mathrm{M}(1-18)$ counterpart, the former interacts more favorably with zwitterionic membranes, which makes it a less appealing drug candidate. Thus, the findings herein reported are of undeniable relevance for the design and development of novel antimicrobial peptides based on the hybridization concept. 
Acknowledgment. M.B. and F.A. thank Dra. M. Salette Reis, Faculty of Pharmacy, University of Porto, for the access to the light scattering instrument, as well as for support and helpful discussion. Thanks are also due to FCT for financial support to CIQ(UP) and for the PhD grant PRAXIS XXI/BD/ 18523/98 (F.A.).

\section{References and Notes}

(1) Boman, H. G. Annu. Rev. Immun. 1995, 13, 61

(2) Boman, H. G. J. Intern. Med. 2004, 254, 197.

(3) Andreu, D.; Rivas, L. Biopolymers 1998, 47, 415. 11 .

(4) Epand, R. M.; Vogel, H. J. Biochim. Byophys. Acta 1999, 1462,

(5) Rivas, L.; Andreu, D. In Pore-forming peptides and protein toxins; Menestrina, G., Dalla Serra, M., Lazarovici, P., Eds.; Taylor and Francis: London, 2003; pp 209-259.

(6) Boman, H. G.; Wade, D.; Boman, A.; Wåhlin, B.; Merrifield, R. B. FEBS Lett. 1989, 259, 103.

(7) Merrifield, R. B.; Merrifield, E. L.; Juvvadi, P.; Andreu, D.; Boman, H. G. Cyba Found. Symp. 1994, 186, 5.

(8) Merrifield, E. L.; Mitchel, S. A.; Ubach, J.; Boman, H. G.; Andreu, D.; Merrifield, R. B. J. Pep. Protein Res. 1995, 46, 214.

(9) Andreu, D.; Ubach, J.; Boman, A.; Wahlin, B.; Wade, D.; Merrifield, R. B.; Boman, H. G. FEBS 1992, 296, 190.

(10) Díaz-Achirica, P.; Prieto, S.; Ubach, J.; Andreu, D.; Rial, E.; Rivas, L. Eur. J. Biochem. 1994, 224, 257.

(11) Diaz-Achirica, P.; Ubach, J.; Guinea, A.; Andreu, D.; Rivas, L. Biochem. J. 1998, 330, 453.

(12) Nos-Barbera, A.; Portoles, M.; Morilla, A.; Ubach, J.; Andreu, D.; Paterson, C. A. Cornea 1997, 16, 101.

(13) Oh, H.; Hedberg, M.; Wade, D.; Edlund, C. Antimicrob. Agents Chemother. 2000, 44, 68.

(14) Saugar, J. M.; Alarcón, T.; Lopez -Hernández, S.; López-Brea, M.; Andreu, D.; Rivas L. Antimicrob. Agents Chemother. 2002, 46, 875. (15) Mancheño, J. M.; Oñaderra, M.; Del Pozo, A. M.; Diaz-Achirica

P.; Andreu, D.; Rivas, L.; Gavilanes, J. G. Biochemistry 1996, 35, 9892.

(16) Lohner, K.; Prenner, E. J. Biochim. Byophys. Acta 1999, 1462, 141.

(17) Hancock, R. E. W.; Scott, M. G. Proc. Natl. Acad. Sci. U.S.A. 2000 97, 8856.

(18) Chicharro, C.; Granata, C.; Lozano, R.; Andreu, D.; Rivas, L. Antimicrob. Agents Chemother. 2001, 45, 2441.

(19) Wimley, W. C.; Hristova, K.; Ladokhin, A. S.; Silvestro, L.; Axelsen, P. H.; White S. H. J. Mol. Biol. 1998, 277, 1091.

(20) Matsuzaki, K. Biochim. Byophys. Acta 1999, 1462, 1.

(21) Marassi, F. M.; Opella, S. J.; Juvvadi, P.; Merrifield, R. B. Biophys. J. 1999, 77, 3152 .

(22) Huang, H. W. Biochemistry 2000, 39, 8347.

(23) Silvestro, L.; Axelsen, P. H. Biophys. J. 2000, 79, 1465.

(24) Naito, A.; Nagao, T.; Norisada, K.; Mizuno, T.; Tuzi, S.; Saitô, H. Biophys. J. 2000, 78, 2405.

(25) Yang, L.; Harroun, T. A.; Weiss, T. M.; Ding, L.; Huang, H. W. Biophys. J. 2001, 81, 1475.

(26) Zhang, L.; Rozek, A.; Hancock, R. W. J. Biol. Chem. 2001, 276, 35714

(27) Chen, F.-Y.; Lee, M.-T.; Huang, H. W. Biophys. J. 2003, 84, 3751.

(28) Chen, H. M.; Leung, K. W.; Thakur, N. N.; Tan, A.; Jack, R. W. Eur. J. Biochem. 2003, 270, 911.
(29) Sitaram, N.; Nagaraj, R. Biochim. Byophys. Acta 1999, 1462, 29. (30) Blondelle, S. E.; Lohner, K.; Aguillar, M. I. Biochim. Byophys. Acta 1999, 1462, 89.

(31) Bishop, C. M.; Walkenhorst, W. F.; Wimley, W. C. J. Mol. Biol. 2001, 309, 975 .

(32) Stella, L.; Mazzuca, C.; Venanzi, M.; Palleschi, A.; Didonè, M. Biophys. J. 2004, 86, 936.

(33) Killian, J. A. FEBS Lett. 2003, 555, 134.

(34) Zhang, Y. P.; Lewis, R. N. A. H.; Hodges, R. S.; McElhaney, R. N. Biochemistry 1992, 31, 11579.

(35) Lohner, K.; Staudegger, E.; Prenner, E. J.; Lewis, R. N. A. H.; Kriechbaum, M.; Degovics, G.; McElhaney, R. N. Biochemistry 1999, 38 , 16514

(36) Contreras, L. M.; Almeida, R. F. M.; Villalaín, J.; Fedorov, A.; Prieto, M. Biophys. J. 2001, 80, 2273.

(37) Rinia, H. A.; Boots, J. W. P.; Rijkers, D. T. S.; Kik, R. A.; Snel, M. M. E.; Demel, R. A.; Killian, J. A.; van der Eerden, J. P. J. M.; Kruiijff, B. Biochemistry 2002, 41, 2814.

(38) Lohner, K.; Latal, A.; Lehrer, R. I.; Ganz, T. Biochemistry 1997, 36,1525 .

(39) Jing, W.; Hunter, H. N.; Hagel, J.; Vogel, H. J. J. Peptide Res. $2003,61,219$.

(40) White, S.; Wimley, W. C.; Ladokhin, A. S.; Hristova, K. Methods Enzymol. 1998, 295, 62.

(41) Blazyk, J.; Wiegand, R.; Klein, J.; Hammer, J.; Epand, R. M.; Epand, R. F.; Lee Maloy W., Kari; U. P. J. Biol. Chem. 2001, 276, 27899.

(42) Chen, F.-Y.; Lee, M.-T.; Huang, H. W. Biophys. J. 2002, 82, 908.

(43) McClare, C. W. F. Anal. Biochem. 1971, 39, 527.

(44) Gomes, P.; Giralt, E.; Andreu, D. Vaccine 2001, 19, 3459.

(45) Chen, Y.-H.; Yang, J. T.; Chau, K. W. Biochemistry 1974, 13, 3350.

(46) Greenfiled, N.; Fasman, G. Biochemistry 1969, 8, 4109.

(47) Wade, D.; Boman, A.; Wåhlin, B.; Drain, C. M.; Andreu, D. Boman, H. G.; Merrifield, R. B. Proc. Natl. Acad. Sci. U.S.A. 1990, 87, 4761.

(48) Zuckermann, M. J.; Heimburg, T. Biophys. J. 2001, 81, 2458. 253.

(50) Ivanova, V. P.; Heimburg, T. Phys. Rev. 2001, E 63, 1914

(51) Heimburg, T. in Planar Lilip Bilayers (BLMs) and their applications; Tien, H. T., Ottova-Leitmannova A., Eds.; Elsevier/North-Holland: Amsterdam, 2003; pp 269-293.

(52) Ivanova, V. P.; Makarov, I. M.; Schäffer, T. E.; Heimburg, T. Biophys. J. 2003, 84, 2427.

(53) Bhargava, K.; Feix, J. B. Biophys. J. 2004, 86, 329.

(54) Matsuzaki, K. Biochim. Biophys. Acta 1998, 1376, 391.

(55) Gazit, E.; Boman, A.; Boman, H. G.; Shai, Y. Biochemistry 1995, $34,11479$.

(56) Kobayashi, S.; Takeshima, K.; Park, C. B.; Kim, S. C.; Matsuzaki, K. Biochemistry 2000, 39, 8648

(57) Lafleur, M.; Samson, I.; Pézolet, M. Chem. Phys. Lipids 1991, 59, 233.

(58) Madeira, C.; Loura, L. M. S.; Aires-Barros, M. R.; Fedorov, A.; Prieto, M. Biophys. J. 2003, 85, 3106.

(59) Dias, R. S.; Lindman, B.; Miguel, M. G. J. Phys. Chem. 2002, 106, 12600.

(60) Fernández, I.; Ubach, J.; Reig, F.; Andreu, D.; Pons, M. Biopolymers 1994, 34, 1251

(61) Dathe, M.; Wieprecht, T. Biochim. Biophys. Acta 1999, 1462, 71. 